Check for updates

Cite this: Mater. Chem. Front. 2020, 4, 3433

Received 29th February 2020, Accepted 15th June 2020

DOI: $10.1039 / \mathrm{dOqm} 00122 \mathrm{~h}$

rsc.li/frontiers-materials

\title{
Recent advances of stable Blatter radicals: synthesis, properties and applications
}

\begin{abstract}
Yu Ji, Lanxin Long and Yonghao Zheng (D) *
Radicals, organic molecules with unpaired electrons, are applied across different scientific disciplines such as electronics, energy storage and biochemistry. Among them, due to the extensive delocalization of the spin on the arene and the endocyclic nitrogens, Blatter radicals possess unique electronic and magnetic properties. Importantly, the excellence of chemical and thermal stability makes them have great potential in applications. In this review, the synthesis, properties and applications of Blatter radicals from recent developments are summarized. Furthermore, the future developments of Blatter radicals are also speculated.
\end{abstract}

\section{Introduction}

The 1,2,4-benzotriazin-4-yl radical, also known as the Blatter radical, was first reported in $1968 .{ }^{1}$ Blatter-type radicals $\mathbf{1}$ have many interesting physical properties such as antiferromagnetism ${ }^{2-7}$ or ferromagnetic interactions, ${ }^{2,7-10}$ spin- $\pi$-delocalization, ${ }^{11}$ narrow electrochemical window ${ }^{12,13}$ and low excitation energy, ${ }^{14,15}$ which allow them to attract more and more attention from scientists. More importantly, Blatter radicals have excellent stability to air and water, and are stable for up to 30 years. ${ }^{16}$ Hence, Blatter radicals have been applied in controllable polymerizations, ${ }^{17,18}$ molecular electronics, ${ }^{19}$ photodetectors, ${ }^{20}$ liquid crystal photoconductors and so on. ${ }^{21}$ In addition, the influence of intramolecular spin-spin interaction on the properties of Blatter diradicals has emerged as an interesting field for exploring their unique properties, such as low energy gap, ambipolarity and convertible spin states in advanced applications. $^{22-26}$

The basic structure of Blatter radicals has three functional aromatic sites. Each of them provides different opportunities to alter their properties. As we can see from Fig. 1, the unpaired electron mainly locates at the triazine core and aromatic site 2 . Interestingly, very little spin is distributed onto the aromatic site 3, which makes it spin isolate. Aromatic site 1: the unpaired electron on 1,2,4-benzotriazinyl is partially delocalized to the aryl group on the $\mathrm{N} 1$ position due to the steric interaction between the aryl substituents of $\mathrm{N} 1$ and the 1,2,4-benzotriazinyl core. The torsional angle between them can be varied with the change of substituents. Modification of the substituents at the $\mathrm{N} 1$ position will significantly affect the molecular packing in

School of Optoelectronic Science and Engineering, University of Electronic Science and Technology of China (UESTC), Chengdu 610054, People's Republic of China. E-mail: zhengyonghao@uestc.edu.cn
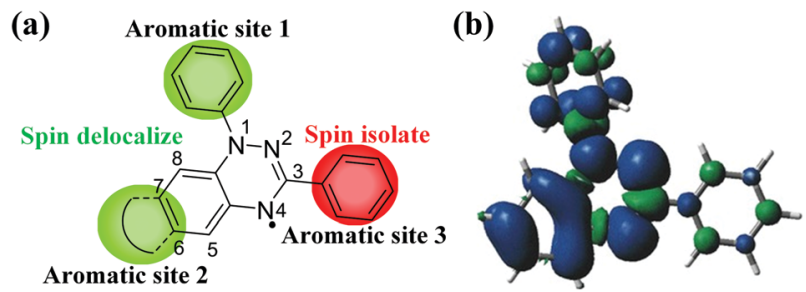

Fig. 1 (a) The structure and (b) spin density distribution of Blatter radicals.

the solid state, leading to a change in the magnetic properties. ${ }^{27,28}$ Aromatic site 2: a large proportion of unpaired electron can resonate at this site. According to the literature, when the $\mathrm{C} 7$ position is not protected by any groups, owing to higher spin density, ${ }^{8,14}$ it is more reactive than the other positions. To prevent the $\mathrm{C} 7$ position from being oxidized to quinone, ${ }^{5,8,18,29-32}$ Koutentis introduced a trifluoromethyl group to make it super stable. ${ }^{8}$ On the other hand, when C6 and $\mathrm{C} 7$ are bridged to aromatic groups, the spin can be further delocalized into the additional aromatic rings. ${ }^{2,3,6,12,33}$ This allows us to induce a spin-spin interaction within or between the molecules, which provides a great chance to investigate the high-spin state and semiconducting properties of $\pi$-extended Blatter radicals. Aromatic site 3: It can be found that the unpaired electron of 1,2,4-benzotriazinyl cannot resonate to the $\mathrm{C} 3$ position. Therefore, the aryl substituents at C3 are spin isolated. However, the introduction of different substituents at the C3 position can impact their physical properties without affecting the properties of radicals. ${ }^{7,9,10,34,35}$

In this review, we discuss the synthesis, properties and applications of a series of Blatter radicals, and describe the future developments and potential applications of Blatter based materials. We hope that this review will encourage more scientists to help Blatter radicals reach their full potential. 


\section{Synthesis}

Koutentis et al. briefly summarized the chemistry and applications of Blatter radicals up to 2016 in their review of stable $\mathrm{N}-$ and N/S-rich heterocyclic radicals. ${ }^{36}$ The synthesis of 1,3-diphenyl-1,4-dihydro-1,2,4-benzotriazin-4-yl (Blatter) was first reported in $1968 .^{1}$ To further improve the yield and simplify the preparation of Blatter radicals, new synthetic routes have been developed by researchers in recent years. According to the different precursors of forming Blatter radicals, the synthesis route is divided into three strategies.

Route 1. This is a classical route to Blatter radicals (1). As shown in Scheme 1a, the ring closure of 2 to 1 occurs at the $\mathrm{N} 1$ position. ${ }^{13}$ The mechanism of route 1 was proposed in the literature. ${ }^{37}$ The conversion of $2 \mathbf{a}$ to $\mathbf{2 b}$ could thus involve two-electron oxidation of $\mathbf{2 a}$ in situ to give the 1,2,4-triazabutadienes $\mathbf{2 b}$, and subsequent ring closure to benzotriazines and further oxidization to Blatter radicals 1. As an alternative, the amidrazone could undergo a one-electron oxidation to a hydrazonyl radical 2c, followed by cyclization to a benzotriazine and further oxidation to yield $\mathbf{1}$. The optimization of this route is mainly composed of two parts, one is the synthesis of $\mathbf{2 a}$, and the other is ring closure from $\mathbf{2 a}$ to $\mathbf{1}$.

In the early time, the most frequently used method for synthesizing $\mathbf{1}$ with $\mathbf{2 a}$ was a product-specific synthesis in moderate yields and involved excessive amounts of mercury oxide or silver oxide as oxidants, which are toxic and expensive. ${ }^{14,16}$ Due to the limitation of synthetic route, its derivatives received little attention. Later, a variety of oxidants have been used in the oxidative cyclization, including palladium-on-carbon $(\mathrm{Pd} / \mathrm{C}) / \mathrm{air} / 1,8-$ diazabicyclo[5.4.0] undec-7-ene (DBU), ${ }^{30,32}$ ruthenium(III) chloride $\left(\mathrm{RuCl}_{3}\right)$ and potassium ferricyanide $\left(\mathrm{K}_{3}\left[\mathrm{Fe}(\mathrm{CN})_{6}\right]\right)$. The most common route is using DBU/air as the final ring closure conditions. Koutentis and coworkers reported a simple and efficient synthetic method of Blatter radicals by adding Pd/C to DBU/air conditions, bringing the yield of radicals 1 to $87-95 \%{ }^{29}$

The following two routes were recently developed (Scheme 1a). In the first route, amidrazones $2 \mathrm{a}$ need to be carefully isolated from the mixture of three products (2a, 3c and $3 \mathbf{d}$ ). The yield of Blatter radicals $\mathbf{1}$ highly depends on the purity of the starting amidrazones 2a. Synthesis and purification of amidrazones $\mathbf{2 a}$ is a critical factor. When the amidrazones have been purified by recrystallization, the yield can be significantly improved (>90\%). However, not all amidrazones can be easily crystallized, and in particular, electron-rich analogues are rapidly oxidized upon storage. The second route, which involves the preparation of 3e and condensation with $\mathbf{3 f}$, minimized the formation of byproducts and is currently the preferred route. ${ }^{13}$

Route 2 . The difference between route 2 and 1 is the oxidative site. The strategy is to form hydrazides $\mathbf{4 a}$ and then cyclodehydrate to radicals 1 (Scheme 1b). The strategy can avoid the formation of highly reactive intermediates, such as the amidrazones $\mathbf{2 a}$ or the imidoyl/hydrazonyl chlorides $\mathbf{3 a}$ and 3e. The optimization of the route consists of two parts, one is the synthesis of hydrazides $\mathbf{4 a}$, and the other is the ring closure from 4 a to 1.

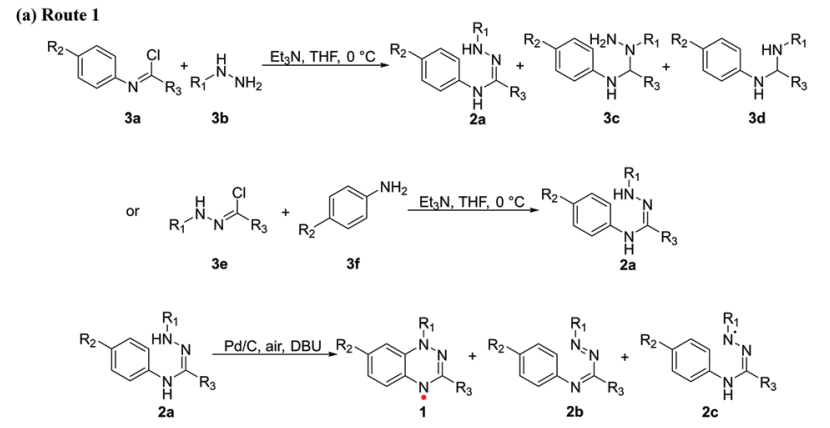

(b) Route 2
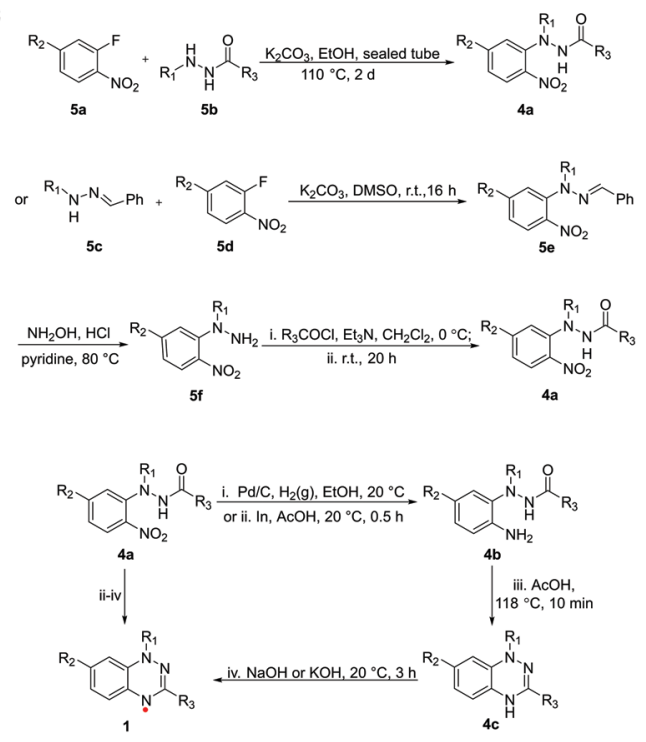

(c) Route 3
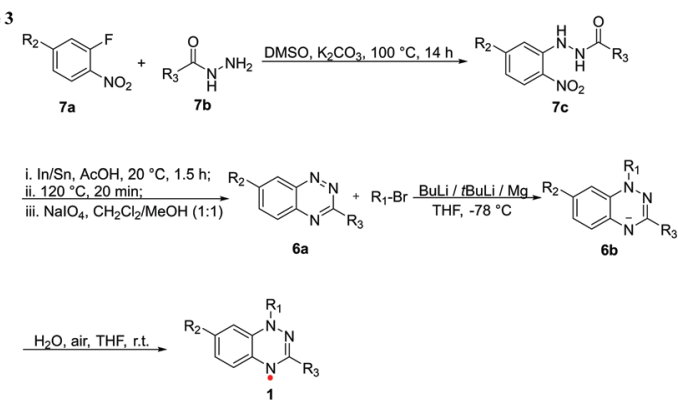

(d) Route 4

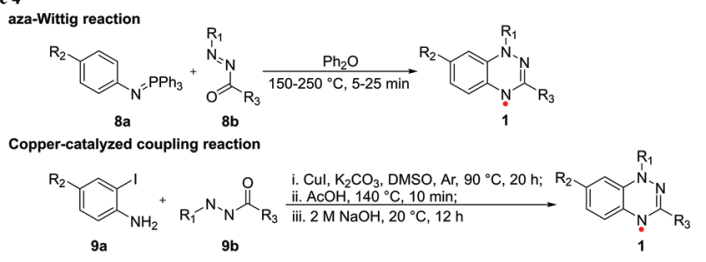

Scheme 1 Synthetic routes of Blatter radicals. $\left(R_{1}=\right.$ aryl; $R_{2}=$ aryl/ heterocyclic aryl, $\mathrm{CF}_{3}, \mathrm{SMe}, \mathrm{Cl}, \mathrm{Br}, \mathrm{I} ; \mathrm{R}_{3}=\operatorname{aryl}, \mathrm{CF}_{3},{ }^{t} \mathrm{Bu}$.)

Koutentis and his coworker developed a route to hydrazides 4a (Scheme 1b). ${ }^{13}$ They substituted halonitroarenes by hydrazides to give compounds 4 a directly. This scheme was specifically developed for analogues with alkyl groups at R3. However, when R3 was methyl or trifluoromethyl, the yield was low. They redesigned the route and introduced the readily available 1-benzylidene-2-phenylhydrazine (5c), which overcame 
this problem through a multi-step route. Their strategy was inspired by the early synthesis route by Blatter et al. ${ }^{1}$ Subsequently, the nitro group in hydrazides $\mathbf{4 a}$ is reduced, and then cyclodehydrated by acid-mediation to obtain the fused triazine. Finally, the desired radicals 1 are obtained after alkali treatment.

The advantage of this route is that it leads to the radical via a stable precursor $\mathbf{4 a}$ and a unimolecular cyclodehydration step. ${ }^{38}$ Furthermore, the R1 and R3 of the precursor $4 a$ can be a range of substituents.

Route 3. The overall yields of the above-mentioned routes are relatively low. Also, they failed under some conditions because of involving either amidrazones or hydrazides as intermediates and low reactivity and regioselectivity of $\mathrm{N}$-acylation. Therefore, post-cyclization ring substitution has been developed in the formation of radicals 1 . The greatest advantage of this route is the vast choices of different functional groups at the N1 position. More importantly, substituents at the N1 position can effectively control the spin distribution, electrochemical properties and intermolecular spin exchange interactions of the Blatter radicals. ${ }^{39}$

In this route, the organometallic reagents $\left({ }^{t} \mathrm{BuLi} / \mathrm{Mg} /{ }^{n} \mathrm{BuLi}\right)$ are added into the solution of benzo-1,2,4-triazines $\mathbf{6 a}$, followed by oxidizing the anion intermediates $\mathbf{6 b}$ to radicals $\mathbf{1}$ in air (Scheme 1c). Benzo-1,2,4-triazines 6a can be easily prepared in a three-step process from benzhydrazides, which were $\mathrm{N}$-arylated with fluoronitrobenzene to form the hydrazides 7c, with subsequent ring closure to $\mathbf{6}$ a under reductive conditions (Scheme 1c), ${ }^{28}$ which is almost the same synthetic protocol used for preparing the compounds described in Route 2. The method is general and permits the introduction of a substituent at the N1 position at the post-cyclization step. ${ }^{39}$ However, this step also requires inert conditions and suffers from poor tolerance of functionalities that are incompatible with aryl or alkyl lithium agents.

Other routes. In addition to the above routes, new methods have been continuously reported, such as aza-Wittig reaction, ${ }^{40}$ copper-catalyzed coupling reaction, ${ }^{7}$ Pschorr-type cyclization $^{39}$ or the use of bench-stable carbene derivatives as intermediates. $^{37}$

The reaction of $\mathrm{N}$-aryliminophosphoranes and 1-(het)aroyl2-aryldiazenes in diphenyl ether leads to the in situ formation of the oxidized amidrazone leading directly to Blatter radicals with moderate to good yields (Scheme 1d). ${ }^{40}$ This short synthesis method is an aza-Wittig reaction, which avoids the formation of moisture sensitive imidoyl chlorides, oxidatively unstable amidrazones, expensive reagents or organolithium bases. It also can introduce a relatively wide range of substituents, providing access to analogues that are difficult to prepare through Routes 1 , 2 and 3.

When Ma's transition metal catalysed couplings are used to couple iodoanilines with hydrazides, the cyclodehydration route becomes shorter, and Blatter radicals are produced in one pot (Scheme 1d). ${ }^{7}$ The synthesis time is shortened, and the total yield is also improved.

Upon the recent developments in the synthesis of Blatter radicals, the design flexibility and structural varieties have been

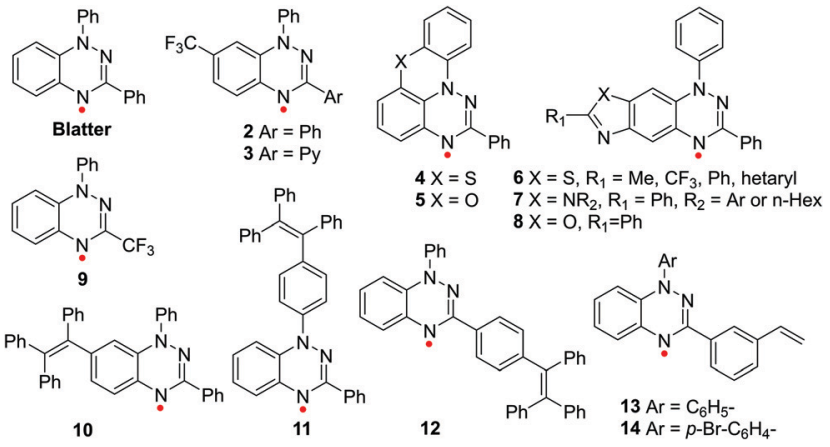

Fig. 2 The structures of selected Blatter radicals.

enhanced significantly (Fig. 2 and 5), which makes them suitable for future applications.

\section{Properties}

\subsection{Chemical stability}

Among the unique properties of Blatter radicals, chemical stability is one of the most important properties, which is the basic premise of any applications. Generally, the radicals are stabilized by increasing the steric hindrance of the spin centers or by delocalizing the unpaired electron. For Blatter radicals, the unpaired electron is not localized at the $\mathrm{N} 4$ position, but can resonate to multiple positions of 1,2,4-benzotriazinyl, forming multiple resonance structures. It is exciting to note that the 1,3-diphenyl-1,4-dihydro-1,2,4-benzotriazin-4-yl prepared by Gazetdinova et al. still retain their properties after 30 years. ${ }^{41}$ Moreover, the introduction of substituents such as trifluoromethyl, thiophenyl, phenyl and 4-fluorophenyl can inhibit oxidation at the $\mathrm{C} 7$ position, thus protecting the spin center and improving the oxidation stability of 1,2,4-benzotriazinyls. Koutentis et al. introduced a trifluoromethyl group to the $\mathrm{C} 7$ position of the Blatter radical and obtained radical 2, which significantly improved the chemical stability of 2 under strong oxidative conditions. $^{8}$ Classic Blatter and compound 2 were treated with either $\mathrm{MnO}_{2}$ or $\mathrm{KMnO}_{4}$ as oxidants, and it was found that Blatter became benzotriazinone after several days, while radical 2 maintained the original structure. Hence, it was called a "super stable" radical. Although in one rare case, oxidative dimerization has occurred to give a new dimer monoradical. ${ }^{42}$

\subsection{Optical and electrical properties}

Because of the conjugated structure of the Blatter radicals, the physical properties can be easily tuned by modifying the molecular structure, which results in different optical and electrical properties. Kaszyński et al. designed planar Blatter radicals by planarizing 1,2,4-benzotriazinyl with sulfur or oxygen at the $\mathrm{C} 8$ and Ph group at the N1 positions, named as $\mathbf{4}$ and 5, respectively. ${ }^{28}$ By expanding $\pi$-conjugation, the spin density of these radicals distributes more on the benzene ring at the $\mathrm{N} 1$ position. Therefore, the absorption is shifted to the near infrared region (Fig. 3a). Furthermore, Blatter radicals have unexpected fluorescent properties since most radicals do not emit. 


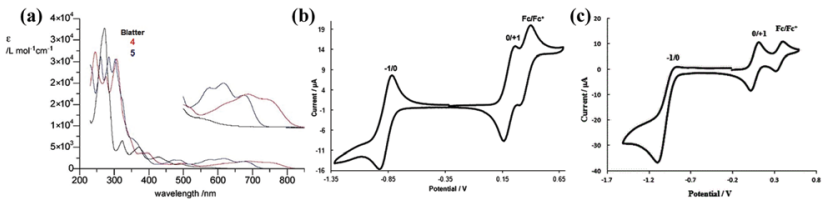

Fig. 3 (a) UV/vis spectra for Blatter (black line), $\mathbf{4}$ (blue line) and $\mathbf{5}$ (red line) in $\mathrm{CH}_{2} \mathrm{Cl}_{2}$. The inset shows the enlarged region $500-850 \mathrm{~nm}$. Reprinted with permission from ref. 28. Copyright 2016 Wiley-VCH. Cyclic voltammograms of (b) thiazolobenzotriazinyl $6(1.0 \mathrm{mM})$ and $(\mathrm{c})$ imidazolobenzotriazinyl $7(1.0 \mathrm{mM}),{ }^{n} \mathrm{Bu}_{4} \mathrm{NPF}_{6} 0.1 \mathrm{M}, \mathrm{DCM}, \mathrm{ca} .20{ }^{\circ} \mathrm{C}, 50 \mathrm{mV} \mathrm{s}^{-1}$. Reprinted with permission from ref. 12 and 33. Copyright 2013 The Royal Society of Chemistry. Copyright 2012 American Chemical Society.

The results showed that when Blatter radicals were spin coated into a film, the fluorescence from the film was quenched, which was due to the formation of dimers/aggregates. However, when radicals were inserted into the solid matrix to inhibit aggregation, the fluorescence was restored. ${ }^{43}$

Koutentis et al. developed a series of $\pi$-extended thiazolo-, imidazolo-, and oxazolo-fused 1,2,4-benzotriazinyls at the C6 and $\mathrm{C} 7$ positions $(6,7$ and 8$) .{ }^{12,33}$ These highly delocalized radicals show good air stability and exhibit great reversible electrochemical behaviour (Fig. $3 \mathrm{~b}$ and c). Thiazolotriazinyls have fully reversible, low oxidation potentials, and a planar spin-bearing acene core, and imidazolotriazinyls have low oxidation potentials within $0.10 \mathrm{~V}$, which makes them good electron donors in the process of donor-acceptor charge transfer.

\subsection{Magnetic properties}

Magnetism is a unique property of organic molecule with unpaired electron(s). ${ }^{34}$ Paramagnetic, ferromagnetic and antiferromagnetic properties are the most commonly found properties in radicals. ${ }^{44-47}$ However, Blatter radicals demonstrate some unusual magnetic behaviours such as metamagnetic transformation, paramagnetic-diamagnetic transformation and intermolecular triplet (quintet) state.

Small structural changes can alter the way of molecular packing in the solid state, resulting in a variety of ferromagnetic and antiferromagnetic behaviours of the Blatter radicals. For example, Koutentis et al. replaced the phenyl group at the C3 position in Blatter with $\mathrm{CF}_{3}(\mathbf{9})$ and found that there is an abrupt and reversible paramagnetic-diamagnetic transformation for the radical at $58(2) \mathrm{K}$ related to crystal transformation (Fig. $4 \mathrm{~b})^{7}$

Controlling the stacking mode of single crystals is very important for the successful design of molecular magnetic materials. The magnetic behaviour of organic radicals highly depends on the type of molecular packing. ${ }^{27}$ Zheng et al. synthesized the stereoisomers of monoradicals 10, 11 and 12 by replacing the three benzene rings with a highly twisted tetraphenylethylene (TPE) moiety. ${ }^{48} \mathbf{1 0}$ and $\mathbf{1 2}$ form zigzag infinite chains and discrete centrosymmetric slipped dimer accumulations, respectively (Fig. $4 \mathrm{c}$ and d). The short spinspin distances $(\sim 4.1 \AA)$ lead to the observation of thermally excited spin triplet state. Furthermore, the $\chi T$ value of $\mathbf{1 0}$ and $\mathbf{1 2}$ at $300 \mathrm{~K}$ is much larger than the theoretical value of an ideal (a)
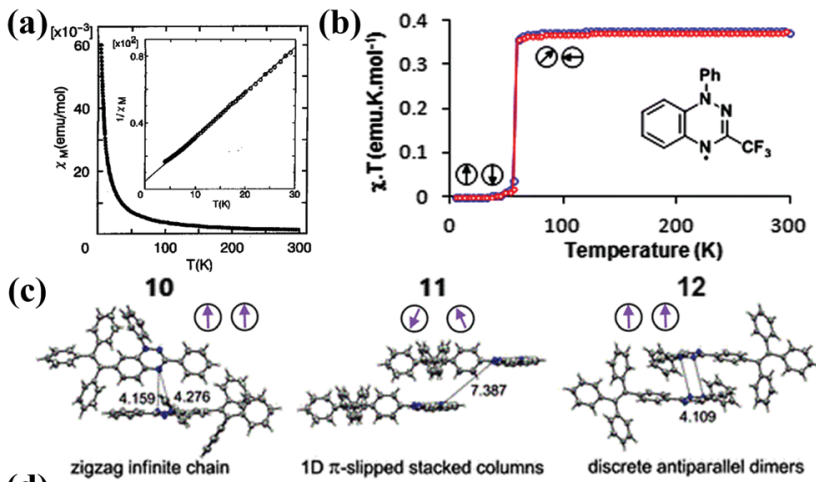

(d)
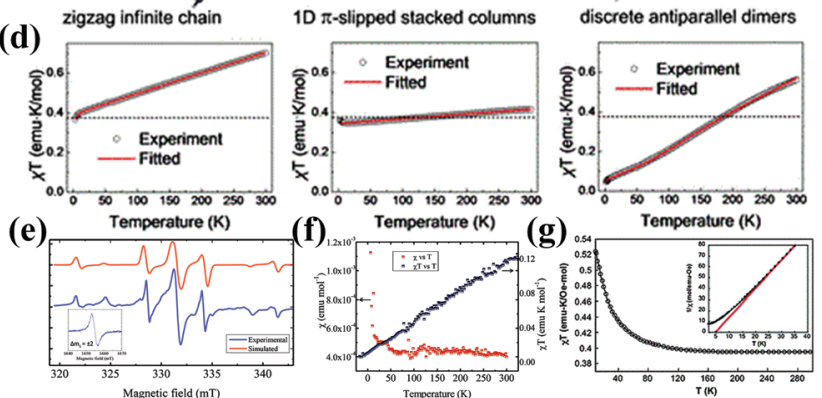

Fig. 4 (a) The temperature dependence of the molar magnetic susceptibility $\left(\chi_{M}\right)$ of Blatter. The inset shows the reciprocal susceptibility $\left(1 / \chi_{M}\right)$ below $30 \mathrm{~K}$. Reprinted with permission from ref. 34. Copyright 1994 Elsevier Science B.V. (b) Temperature dependence of $\chi^{T}$ upon cooling (blue $O$ ) and heating (red $O$ ) for 9 between 5 and 300 K. Reprinted with permission from ref. 7. Copyright 2014 American Chemical Society. (c) Partial solid-state packing diagrams of 10,11 and 12. (d) Temperaturedependent plots of $\chi^{T}$ for $\mathbf{1 0}, \mathbf{1 1}$ and $\mathbf{1 2}$ measured at $1.0 \mathrm{~T}$ in the stable mode from 2 to $300 \mathrm{~K}$. Reprinted with permission from ref. 48. Copyright 2019 American Chemical Society. (e) ESR $(9.3018 \mathrm{GHz})$ spectrum of 15 in a polycrystalline solid at room temperature (blue) corresponding to the dipolar coupling between two $S=1$ spin systems. Inset: $\Delta M_{s}= \pm 2$ : (microwave frequency $9.2962 \mathrm{GHz}$ ) in a polycrystalline solid at room temperature. (f) Temperature-dependent $\chi$ and $\chi^{T}$ versus $T$ plot for solid 15 at 100 Oe. Reprinted with permission from ref. 20. Copyright 2015 Wiley-VCH. (g) Temperature-dependence of the molar magnetic moment at $1.0 \mathrm{~T}$ and inverse susceptibility (inset) for radical 13 with Curie-Weiss fit. Reprinted with permission from ref. 9. Copyright 2011 The Royal Society of Chemistry.

monoradical, and the $\chi T$ value of $\mathbf{1 2}$ drops sharply from $0.56 \mathrm{emu} \mathrm{K} \mathrm{mol}{ }^{-1}$ to $0.05 \mathrm{emu} \mathrm{K} \mathrm{mol}{ }^{-1}$ when cooled from 300 to $2 \mathrm{~K}$. In contrast, because of the $1 \mathrm{D}$ slipped stacked columns and long spin-spin distance (>7.3 ̊) (Fig. 4c and d), 11 shows weak intermolecular interaction, thus exhibiting paramagnetism and showing almost ideal Curie-Wiess behaviour at $2-300 \mathrm{~K}$.

Increasing spin delocalization can further stabilize $\pi$ radicals and enhance solid-state ferromagnetic exchange, which can serve as promising building blocks for magnetic materials. Wudl et al. first synthesized an organic diradicaloid based on stable benzotriazinyls $(\mathbf{1 5}) \cdot{ }^{20}$ In the solid state, molecules 15 form dimers due to the face-to-face $\pi-\pi$ interactions. The ESR spectrum of the polycrystalline sample of $\mathbf{1 5}$ presents an unprecedented intermolecular quintet state at room temperature (Fig. 4e and f).

Frank et al. reported two Blatter radicals 13 and $\mathbf{1 4}$ with strong spin delocalization due to their unique planar 

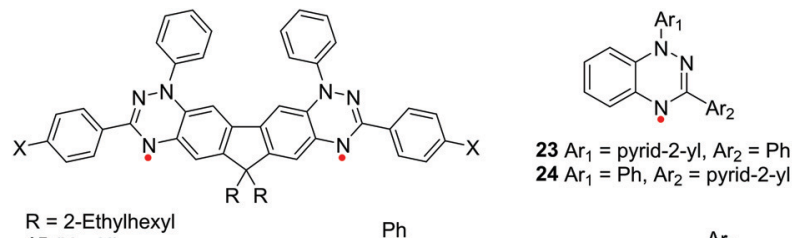

$$
\begin{aligned}
& 15(X=H) \\
& 16(X=B r)
\end{aligned}
$$<smiles></smiles>

$\mathrm{R}=\mathrm{C}_{12} \mathrm{H}_{25} \mathrm{O}$

$18 \mathrm{Ar}=\mathrm{Ph}$

$19 \mathrm{Ar}=\mathrm{C}_{6} \mathrm{H}_{4}-3-\mathrm{F}$

$20 \mathrm{Ar}=\mathrm{C}_{6} \mathrm{H}_{2}\left(\mathrm{OC}_{12} \mathrm{H}_{25}\right)_{3}-3,4,5$

$21 \mathrm{Ar}=\mathrm{C}_{6} \mathrm{H}_{2}\left(\mathrm{SC}_{12} \mathrm{H}_{25}\right)_{3}-3,4,5$
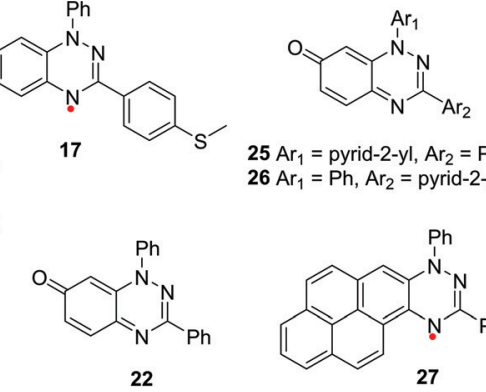

$25 \mathrm{Ar}_{1}=$ pyrid-2-yl, $\mathrm{Ar}_{2}=\mathrm{Ph}$ $26 \mathrm{Ar}_{1}=\mathrm{Ph}, \mathrm{Ar}_{2}=$ pyrid-2-yl

Fig. 5 The structure of selected Blatter radicals and benzo[1,2,4]triazin-7one derivatives.

open-shell electron structure. ${ }^{9} \mathbf{1 3}$ and 14 form $1 \mathrm{D}$ chains with a large degree of slippage, leading to direct face-to-face $\pi-\pi$ interactions between 1,2,4-benzotriazinyls. In addition, there are edge-to-face $\pi-\pi$ interactions between $\pi$ stacks, which leads to the $\pi-\pi$ interaction in three dimensions. Therefore, 13 and 14 present intrachain ferromagnetic and interchain antiferromagnetic exchange interactions, resulting in metamagnetic behaviour (Fig. 4g).

\section{Applications}

\subsection{Semiconductor related applications}

Compared with inorganic materials, organic semiconductors not only have tuneable structures, but also have the advantages of low cost, low treatment temperature, solution processing and flexibility. Since the discovery of conductive polymers, organic semiconductors have attracted much attention for their potential applications in the field of organic field-effect transistors, organic light-emitting diodes and organic photovoltaics. $^{49-51}$ To date, closed-shell molecules are much more popular than molecules with unpaired electrons. The main reason behind this unbalanced development is that openshell molecules are synthetically more difficult with much lower stability. Therefore, Blatter radicals come to our sight. Blatter radicals are highly delocalized with good chemical and photo stabilities and reversible electrochemical behaviour, which makes them very suitable for semiconductors. In addition, when there are heteroatoms in the radicals, the intermolecular contact can be enhanced, which is conducive to increasing the molecular interactions and conductivity. These excellent properties are beneficial to the applications of Blatter radicals in electronic devices. The several applications of Blatter radicals are introduced as follows.

4.1.1 NIR photodetectors. Diradical 15 has wide absorbance across the UV-vis-NIR region and was applied in a near-infrared (NIR) photodetector (Fig. 6a). ${ }^{20}$ When 15 and $[6,6]$-phenyl $\mathrm{C}_{61}$ butyric acid methyl ester (PCBM) were mixed
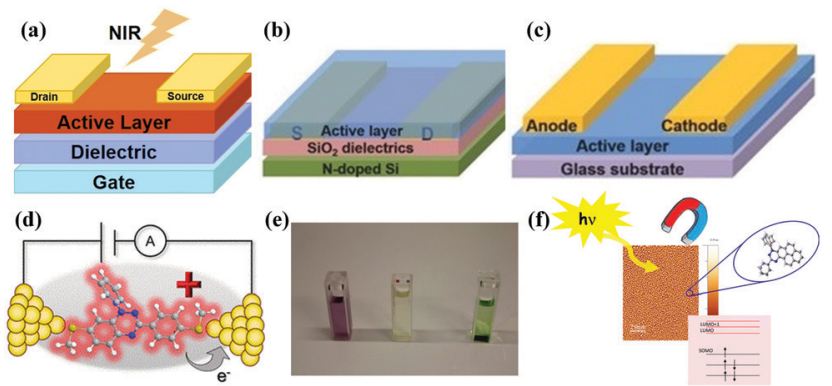

Fig. 6 (a) NIR photodetector device architecture. (b) and (c) OFET and planar diode device architectures. Reprinted with permission from ref. 19. Copyright 2015 Wiley-VCH. (d) Illustration of a single-molecule junction. Reprinted with permission from ref. 52. Copyright 2019 American Chemical Society. (e) Photograph of a solution of 27 (purple), PA (pale yellow) and the mixture (green). Reprinted with permission from ref. 3 . Copyright 2014 Wiley-VCH. (f) Metal-free magnet for stable thin films and interfaces. Reprinted with permission from ref. 55. Copyright 2016 American Chemical Society.

in the ratio of $1: 2$, the corresponding photodetectors showed high responsivity and detectivity between 300 and $1200 \mathrm{~nm}$ (Fig. 7a and b). The detectivity exceeded $10^{11} \mathrm{~cm} \mathrm{~Hz}^{1 / 2} \mathrm{~W}^{-1}$ at $1200 \mathrm{~nm}$ (Fig. 7c). The photodetector was comparable to other organic photodetectors, and Si and InGaAs photodetectors.

4.1.2 OFET and planar diode devices. Wudl et al. synthesized two benzotriazine diradicals 15 and $16 .{ }^{19}$ Because the intermolecular electron transferred between the open-shell and the closed-shell in 15 and 16, radical anion-radical cation pairs were formed. An unprecedented self-doped behaviour has been observed based on OFET devices (Fig. 6b), showing typical p-type OFET characteristics, with hole mobility of $\mu_{\mathrm{h}}=1.7 \times$ $10^{-5} \mathrm{~cm}^{2} \mathrm{~V}^{-1} \mathrm{~s}^{-1}(15)$ and $\mu_{\mathrm{h}}=2.4 \times 10^{-5} \mathrm{~cm}^{2} \mathrm{~V}^{-1} \mathrm{~s}^{-1}$ (16). Moreover, the number of radical anion-radical cation pairs of 15 and 16 was reversible and adjustable with change in temperature, so the transmission characteristics of OFET devices could be reversibly adjusted by using the external conditions. In addition, when the strong electron acceptor 2,3,5,6-tetrafluoro7,7,8,8-tetrcyano-dimethane (F4TCNQ) was further added, the doping effect of F4TCNQ in 15 at $300 \mathrm{~K}$ almost overlapped with that of the original 15 at $370 \mathrm{~K}$. In general, devices based on these diradicals achieved controlled and reversible self-doping effects that cannot be generated by conventional chemical doping.

4.1.3 Single-molecule device. Venkataraman et al. found that stable organic radicals could be used to construct organic spintronic devices based on single-molecule junction (Fig. 6d) by well characterizing the interface between organic radicals and metal electrodes. ${ }^{52}$ They studied the electronic interaction between the Blatter radical $\mathbf{1 7}$ and the gold metal electrode through the single-molecule conductance measurement. It was observed that under ultra-high vacuum, 17 was stable when adsorbing on a gold substrate and its open shell radical property was maintained. Moreover, the conducting electrons scattered off unpaired electrons to produce Kondo resonance.

Patera et al. also studied the geometry and electronic structure of 17 deposited on $\mathrm{Au}(111)$ by high resolution non-contact 

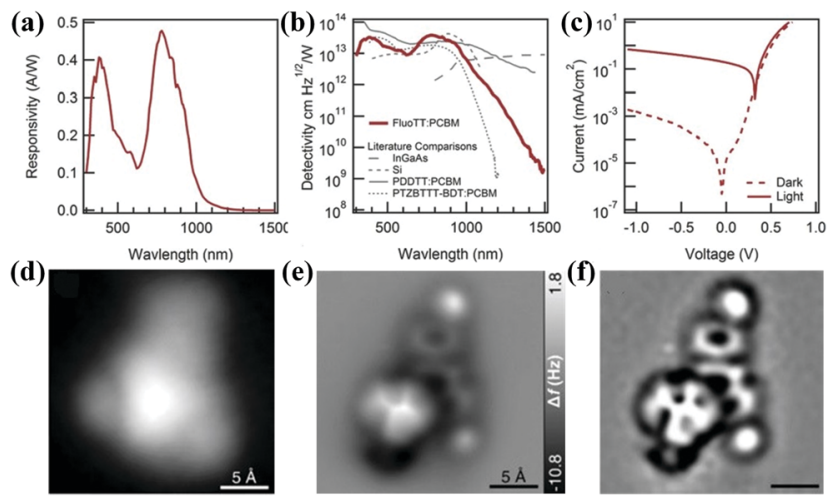

Fig. 7 Photodetector characteristics of 15:PCBM (1:2, films annealed at $80{ }^{\circ} \mathrm{C}$ for $5 \mathrm{~min}$ ) including (a) light (white light) and dark $\mathrm{J}-\mathrm{V}$ curves; (b) responsivity; and (c) detectivity of the devices compared with literature values of detectivity for other photodetectors. Reprinted with permission from ref. 20. Copyright 2015 Wiley-VCH. Blatter radical on Au(111). (d) Constant-current STM image acquired with a metal tip $(I=3.8 \mathrm{pA}$, $V=0.1 \mathrm{~V}$ ). (e) Constant-height AFM image acquired with a COfunctionalized tip, at a z-offset of $2.4 \AA$ with respect to a STM set-point of $(I=0.7 \mathrm{pA}, V=0.5 \mathrm{~V})$. (f) High-pass (Laplace)-filtered image of (e). Reprinted with permission from ref. 53. Copyright 2019 Wiley-VCH.

atomic force microscopy (AFM), scanning tunneling microscopy (STM) and scanning tunneling spectroscopy (STS) (Fig. 7d and e). ${ }^{53}$ The spatial distribution of the Kondo resonance was explored and obtained the spatial distribution of the singly occupied molecular orbitals (SOMO), and even showed the node plane structure of the corresponding orbitals. These results demonstrated that the Kondo resonance was state-selective when entering the molecular state responsible for spin-metal coupling, and thus achieved enhanced imaging resolution despite orbital and metal substrate hybridization. Furthermore, such spatial signature of the Kondo resonance also allows the non-covalent dimerization of molecules.

4.1.4 Liquid crystalline photoconductors. Kaszyński et al. reported the substitution of benzo[e][1,2,4]triazinyl ring with 3,4,5- $\left(\mathrm{C}_{12} \mathrm{H}_{25} \mathrm{O}\right)_{3} \mathrm{C}_{6} \mathrm{H}_{2}$ groups at the $\mathrm{C} 3$ and $\mathrm{C} 6$ positions, and connected different aryl substituents at the $\mathrm{N} 1$ position to form derivatives of 18-21, which showed $\mathrm{Col}_{\mathrm{h}}$ phase below $80{ }^{\circ} \mathrm{C} .{ }^{21}$ They proved that benzo[e][1,2,4]-triazinyl was an effective spincontaining structural element of photoconductive discotic mesogens, and the type of interactions of radicals in the crystalline phase could be induced by different sizes of aryl substituents at the N1 position. Time-of-flight (TOF) measurements showed that $\mathbf{1 8}$ and $\mathbf{2 0}$ exhibited photoinduced hole transport in the $\mathrm{Col}_{\mathrm{h}}$ phase in the temperature range of 50-70 ${ }^{\circ} \mathrm{C}$ without electric field dependency, with hole mobility of $1.4 \times 10^{-3}$ and $1.3 \times 10^{-3} \mathrm{~cm}^{2} \mathrm{~V}^{-1} \mathrm{~s}^{-1}$, respectively.

\subsection{Other applications}

4.2.1 Anti-cancer activity. Aldabbagh et al. studied the cytotoxicity of benzotriazinyl radicals and compared them with the oxidation products. ${ }^{54}$ It was found that the cytotoxicity of benzotriazinyl radicals 23 and $\mathbf{2 4}$ to cancer cell lines was several orders of magnitude lower than that of benzo[1,2,4]triazin-7one 25 and 26. In addition, the addition of pyridine could significantly change the cytotoxicity against certain cancer cell lines. In 25 and 26, the substitution of the phenyl group with pyrid-2-yl group increased the cytotoxicity.

4.2.2 pH sensor. Wudl et al. reported stable pyrenotriazinyl radicals (27) for the first time and conducted chemical $\mathrm{pH}$ sensing experiments, and found out which had a good sensitivity to Picric acid (PA). ${ }^{3}$ When exposed to PA, the colour of the PyT solution changed from purple to green (Fig. 6e), and the detection limit was $5.0 \times 10^{-6} \mathrm{M}$. As could be seen from the UV-vis spectrum, when 27 and PA were fully mixed, the characteristic absorption of 27 at $400 \mathrm{~nm}$ completely disappeared, and a new broadband appeared at $670 \mathrm{~nm}$. The mechanism behind the colour change of the 27 solution treated with PA was the protonation of the blue radical 27 to form the green radical cation. When adding a base to protonated 27 solution, it restored the original colour of 27.

4.2.3 Metal-free magnet for stable thin films and interfaces. By adjusting the thermodynamic factors, the designed molecules would have good film-forming properties and stability. As we all know, pyrene has a relatively high vapor pressure $(\sim 5.4 \times$ $10^{-4} \mathrm{~Pa}$ ) at room temperature. Casu et al. reported radical 27 , which had lower vapor pressure and good film forming properties (Fig. 6f). ${ }^{55}$ Organic thin films for device contact/substrate were prepared by organic molecular beam deposition (OMBD). The electronic structure, paramagnetic character and stability of the films under the conditions of ultrahigh pressure and environment were studied, which were in accordance with the expected results. Moreover, the paramagnetic property of the molecule was also maintained in the film for a long time. This design provided guidance for the future use of radical based materials in film related devices.

In addition, Blatter radicals have potential applications in controlled polymerization, ${ }^{17,18}$ the building blocks of organic magnetic materials, chelating metal ions, ${ }^{56}$ pressure sensitive semiconductors, ${ }^{57}$ metal-organic frameworks (MOFs) ${ }^{58}$ and other aspects.

\section{Perspectives}

Blatter radicals can be easily modified to have desired properties, which cover the area of chemistry, physical science and biology. To expand the influence of Blatter based materials in the scientific field, we propose the future developments as follows:

\subsection{Organic electronic devices}

Although most of the mainstream electronic devices use inorganic semiconductors, organic semiconductors have the advantages of solution-processing, rich variety, flexibility, large area and so on, which make up for the shortcomings of inorganic semiconductors. ${ }^{59,60}$ Unlike traditional organic materials, open-shell molecules possess unpaired electrons which leads to unique electronic, optical and magnetic properties. ${ }^{19,20,22,23,25,61-66}$ Open-shell molecules already show some potential in organic based devices. ${ }^{19-21,52,53}$ However, the issue of synthetic difficulty and stability in radical containing molecules hold it back for 
further development in electronic applications. Therefore, Blatter radicals are promising candidates to be built in devices. The structure of Blatter radicals can be further optimized by the following methods to improve their performance in electronic devices (OFETs, Organic photoelectric detectors (OPDs) and single-molecule devices): (a) Intrinsic properties: adjusting absorption and energy levels by introducing strong electron donating/withdrawing groups, extending the conjugation and planarizing the molecule by using a smaller group in the N1 position; (b) Extrinsic properties (film morphology): enhancing the dipole-dipole interaction between molecules and adjusting the solubilizing group.

\subsection{Single-molecule devices}

With the continuous progress of science and technology, the miniaturization and high integration of electronic devices will become the inevitable trend of information technology development in the future. The molecular device constructed by coupling single or multiple molecules between electrodes, on the basis of the traditional device function, can realize device miniaturization. ${ }^{67-72}$ Compared with close-shell molecules, open-shell organic radicals with unpaired electrons have spin properties, which can significantly improve the function of information storage, processing and transmission of corresponding molecular devices. ${ }^{73-75}$ It has been reported that monoradical molecules interact with metal or electrode surfaces to prepare single-molecule devices. ${ }^{52,76-78}$ In the field of spintronics, compared with monoradicals, the spin-spin coupling in diradicals is smaller, so it has the characteristics of low energy gap and magnetic tunability. The low energy gap of diradicals can reduce the tunnelling barrier effectively and thus improve the conductivity. ${ }^{79}$ The diradicals themselves have resonance forms and multi-electron states, so their unpaired electrons are not easy to be completely reacted or quenched by the external environment. Therefore, they are suitable for the preparation of single-molecule spin devices.

Blatter-based diradicals have excellent chemical, thermal and optical stabilities. ${ }^{20,80,81}$ Moreover, the delocalization of Blatter radicals is excellent in that the unpaired electrons can be distributed on the triazine ring, which can greatly increase the interaction probability of conducting electrons and unpaired electrons in single-molecule devices. It can be designed to introduce anchoring groups into the Blatter diradicals to explore the influence of the type and position of the anchoring groups.

\subsection{Dynamic nuclear polarization}

In the past 40 years, magic angular rotation (MAS) NMR has become an important analytical method for many physical, chemical and biological problems. ${ }^{82-85}$ However, the sensitivity of NMR is very low, and many experiments need a long time to get enough signal-to-noise ratio. Dynamic nuclear polarization (DNP) is an effective method to enhance the sensitivity of NMR. Combining with magic angle rotating solid-state NMR technology, DNP has been widely used in investigating the structural dynamics of membrane proteins, amyloid proteins, functional porous materials and nanoparticles. ${ }^{86-90}$ DNP is a kind of double resonance technology of electrons and protons. The samples containing radicals are irradiated by RF near the electron lamore frequency. The polarization of electrons can be transferred to the hydrogen protons through electron nucleus coupling in order to enhance the polarization of protons. For the samples containing radicals, DNP can significantly improve the sensitivity of NMR, which can enhance the NMR signal by 1-3 orders of magnitude. ${ }^{91-93}$ In particular, compared with monoradicals, DNP can be greatly enhanced at low electron concentrations by using biradicals as polarizers due to the intramolecular e-e dipole coupling of biradicals. ${ }^{94}$ In addition, molecular linewidth and relaxation directly affect the properties of DNP.

Compared with other types of radicals, Blatter radicals have overall advantages to be successful in the study of DNP. They have unique physical and chemical properties and can be used as DNP reagents. The unpaired electrons of Blatter radicals are more delocalized in the whole molecule, which is beneficial to be polarized. Also, the properties of molecular linewidth and relaxation in Blatter radicals can be easily adjusted by modifying the molecular structures. Hydrophilic groups can also be introduced into Blatter radicals to enhance their water solubility. The applications of Blatter radicals as a polarizer in protein structure research and other biological fields can be explored by combining magic angle rotating solid-state NMR technology.

\subsection{Rechargeable batteries}

At present, with the increasing demand for energy in the world and the limitation of fossil fuel reserves, people are committed to finding and developing new renewable energy. ${ }^{95}$ One of the main signatures of radical compounds is their reversible redox properties. $^{96-98}$ So far, polymeric and small molecule based radical containing materials have been used in rechargeable batteries and more importantly, the NEC company demonstrated a commercial flexible battery with radical based materials in 2015..$^{98-101}$ One of the main problems for radical based batteries is short lifetime (low stability). In principle, Blatter radicals can overcome this issue due to their excellent chemical stability. Indeed, the overall molecular weight of Blatter radicals is normally heavier than the TEMPO based materials. This is not ideal for high capacitance batteries. However, we can easily design the Blatter radicals to have multiple redox properties which means more energy can be store in a single molecule. In addition, Blatter radicals will have a better conductivity than those non-conjugated radical based materials.

While we were writing the review, we found that the use of Blatter radicals in batteries has been patented by the Schubert group. ${ }^{102}$ Furthermore, a Blatter triradical was also recently synthesized and characterized. ${ }^{38}$

\section{Summary}

In this review, the latest developments of Blatter radicals are summarized. Blatter radicals possess many attractive properties 
for researchers to explore in different disciplines. In particular, the areas of organic electronics, DNP and rechargeable batteries are the promising fields to fulfill the potential of Blatter radicals.

\section{Conflicts of interest}

There are no conflicts to declare.

\section{Acknowledgements}

The authors acknowledge the financial support from the National Natural Science Foundation of China (61805034), the Scientific Research Foundation of UESTC for Young Teachers (Y03019023601008007) and the basic frontier project of Fundamental Research Funds for the Central Universities (A03019023801141). This work was also sponsored by Sichuan Province Key Laboratory of Display Science and Technology.

\section{References}

1 H. M. Blatter and H. Lukaszewsk, A New Stable Free Radical, Tetrahedron Lett., 1968, 2701-2705.

2 C. P. Constantinides, A. A. Berezin, M. Manoli, G. M. Leitus, G. A. Zissimou, M. Bendikov, J. M. Rawson and P. A. Koutentis, Structural, magnetic, and computational correlations of some imidazolo-fused 1,2,4-benzotriazinyl radicals, Chem. - Eur. J., 2014, 20, 5388-5396.

3 Y. Zheng, M. Miao, M. C. Kemei, R. Seshadri and F. Wudl, The Pyreno-Triazinyl Radical-Magnetic and Sensor Properties, Isr. J. Chem., 2014, 54, 774-778.

4 Y. Miura and N. Yoshioka, $\pi$-Stacked structure of thiadiazolo-fused benzotriazinyl radical: Crystal structure and magnetic properties, Chem. Phys. Lett., 2015, 626, 11-14.

5 C. P. Constantinides, P. A. Koutentis and J. M. Rawson, Antiferromagnetic interactions in 1D Heisenberg linear chains of 7-(4-fluorophenyl) and 7-phenyl-substituted 1,3diphenyl-1,4-dihydro-1,2,4-benzotriazin-4-yl radicals, Chem. Eur. J., 2012, 18, 15433-15438.

6 C. P. Constantinides, A. A. Berezin, M. Manoli, G. M. Leitus, M. Bendikov, J. M. Rawson and P. A. Koutentis, Effective exchange coupling in alternating-chains of a $\pi$-extended 1,2,4-benzotriazin-4-yl, New J. Chem., 2014, 38, 949-954.

7 C. P. Constantinides, A. A. Berezin, G. A. Zissimou, M. Manoli, G. M. Leitus, M. Bendikov, M. R. Probert, J. M. Rawson and P. A. Koutentis, A magnetostructural investigation of an abrupt spin transition for 1-phenyl-3-trifluoromethyl-1,4-dihydrobenzo[e][1,2,4]triazin-4-yl, J. Am. Chem. Soc., 2014, 136, 11906-11909.

8 C. P. Constantinides, P. A. Koutentis, H. Krassos, J. M. Rawson and A. J. Tasiopoulos, Characterization and magnetic properties of a "super stable" radical 1,3-diphenyl7-trifluoromethyl-1,4-dihydro-1,2,4-benzotriazin-4-yl, J. Org. Chem., 2011, 76, 2798-2806.
9 B. Yan, J. Cramen, R. McDonald and N. L. Frank, Ferromagnetic spin-delocalized electron donors for multifunctional materials: $\pi$-conjugated benzotriazinyl radicals, Chem. Commun., 2011, 47, 3201-3203.

10 Y. Takahashi, Y. Miura and N. Yoshioka, Synthesis and properties of the 3-tert-butyl-7-trifluoromethyl-1,4-dihydro1-phenyl-1,2,4-benzotriazin-4-yl radical, New J. Chem., 2015, 39, 4783-4789.

11 F. A. Neugebauer and G. Rimmler, ENDOR and Triple Resonance Studies of 1,4-Dihydro-1,2,4-benzotriazinyl Radicals and 1,4-Dihydro-1,2,4-benzotriazine Radical Cations, Magn. Reson. Chem., 1988, 26, 595-600.

12 A. A. Berezin, C. P. Constantinides, S. I. Mirallai, M. Manoli, L. L. Cao, J. M. Rawson and P. A. Koutentis, Synthesis and properties of imidazolo-fused benzotriazinyl radicals, Org. Biomol. Chem., 2013, 11, 6780-6795.

13 A. A. Berezin, G. Zissimou, C. P. Constantinides, Y. Beldjoudi, J. M. Rawson and P. A. Koutentis, Route to benzo- and pyrido-fused 1,2,4-triazinyl radicals via $N^{\prime}$-(het)aryl- $N^{\prime}$-[2-nitro(het)aryl]hydrazides, J. Org. Chem., 2014, 79, 314-327.

14 F. A. Neugebauer and I. Umminger, Über 1,4-Dihydro-l,2,4benzotriazinyl-Radikale, Chem. Ber., 1980, 113, 1205-1225.

15 A. Bodzioch, M. Zheng, P. Kaszyński and G. Utecht, Functional group transformations in derivatives of 1,4-dihydrobenzo[1,2,4]triazinyl radical, J. Org. Chem., 2014, 79, 7294-7310.

16 F. A. Neugebauer and I. Umminger, 1,4-Dihydro-1,2,4benzotriazin-Radikalkationen, Chem, Ber., 1981, 114, 2423-2430.

17 J. Areephong, K. M. Mattson, N. J. Treat, S. O. Poelma, J. W. Kramer, H. A. Sprafke, A. A. Latimer, J. Read de Alaniz and C. J. Hawker, Triazine-mediated controlled radical polymerization: new unimolecular initiators, Polym. Chem., 2016, 7, 370-374.

18 M. Demetriou, A. A. Berezin, P. A. Koutentis and T. KrasiaChristoforou, Benzotriazinyl-mediated controlled radical polymerization of styrene, Polym. Int., 2014, 63, 674-679.

19 Y. Zhang, Y. Zheng, H. Zhou, M. S. Miao, F. Wudl and T. Q. Nguyen, Temperature Tunable Self-Doping in Stable Diradicaloid Thin-Film Devices, Adv. Mater., 2015, 27, 7412-7419.

20 Y. Zheng, M. S. Miao, G. Dantelle, N. D. Eisenmenger, G. Wu, I. Yavuz, M. L. Chabinyc, K. N. Houk and F. Wudl, A solid-state effect responsible for an organic quintet state at room temperature and ambient pressure, Adv. Mater., 2015, 27, 1718-1723.

21 M. Jasinski, J. Szczytko, D. Pociecha, H. Monobe and P. Kaszyński, Substituent-Dependent Magnetic Behavior of Discotic Benzo[e][1,2,4]triazinyls, J. Am. Chem. Soc., 2016, 138, 9421-9424.

22 A. Rajca, Organic diradicals and polyradicals: from spin coupling to magnetism?, Chem. Rev., 1994, 94, 871-893.

23 Z. Zeng, X. Shi, C. Chi, J. T. L. Navarrete, J. Casado and $\mathrm{J}$. Wu, Pro-aromatic and anti-aromatic $\pi$-conjugated molecules: an irresistible wish to be diradicals, Chem. Soc. Rev., 2015, 44, 6578-6596. 
24 D. Yuan, Y. Guo, Y. Zeng, Q. Fan, J. Wang, Y. Yi and X. Zhu, Air-Stable n-Type Thermoelectric Materials Enabled by Organic Diradicaloids, Angew. Chem., Int. Ed., 2019, 58, 4958-4962.

25 M. Abe, Diradicals, Chem. Rev., 2013, 113, 7011-7088.

$26 \mathrm{X}$. Hu, W. Wang, D. Wang and Y. Zheng, The electronic applications of stable diradicaloids: present and future, J. Mater. Chem. C, 2018, 6, 11232-11242.

27 A. Gardias, P. Kaszyński, E. Obijalska, D. Trzybinski, S. Domagala, K. Wozniak and J. Szczytko, Magnetostructural Investigation of Orthogonal 1-Aryl-3-Phenyl-1,4Dihydrobenzo[e][1,2,4]triazin-4-yl Derivatives, Chem. Eur. J., 2018, 24, 1317-1329.

28 P. Kaszyński, C. P. Constantinides and V. G. Young, Jr., The Planar Blatter Radical: Structural Chemistry of 1,4-Dihydrobenzo[e][1,2,4]triazin-4-yls, Angew. Chem., Int. Ed., 2016, 55, 11149-11152.

29 P. A. Koutentis and D. L. Re, Catalytic Oxidation of N-Phenylamidrazones to 1,3-Diphenyl-1,4-dihydro-1,2,4benzotriazin-4-yls: An Improved Synthesis of Blatter's Radical, Synthesis, 2010, 2075-2079.

30 C. P. Constantinides, P. A. Koutentis and G. Loizou, Synthesis of 7-aryl/heteraryl-1,3-diphenyl-1,2,4-benzotriazinyls via palladium catalyzed Stille and Suzuki-Miyaura reactions, Org. Biomol. Chem., 2011, 9, 3122-3125.

31 C. P. Constantinides, E. Carter, D. M. Murphy, M. Manoli, G. M. Leitus, M. Bendikov, J. M. Rawson and P. A. Koutentis, Spin-triplet excitons in 1,3-diphenyl-7-(fur-2yl)-1,4-dihydro-1,2,4-benzotriazin-4-yl, Chem. Commun., 2013, 49, 8662-8664.

32 C. P. Constantinides, P. A. Koutentis and J. M. Rawson, Ferromagnetic interactions in a $1 \mathrm{D}$ alternating linear chain of pi-stacked 1,3-diphenyl-7-(thien-2-yl)-1,4-dihydro-1,2,4-benzotriazin-4-yl radicals, Chem. - Eur. J., 2012, 18, 7109-7116.

33 A. A. Berezin, C. P. Constantinides, C. Drouza, M. Manoli and P. A. Koutentis, From Blatter Radical to 7-Substituted 1,3-Diphenyl-1,4-dihydrothiazolo[5' $\left.4^{\prime}: 4,5\right]$-benzo[1,2-e $][1,2,4]$ triazin-4-yls: Toward Multifunctional Materials, Org. Lett., 2012, 14, 5586-5589.

34 K. Mukai, K. Inoue, N. Achiwa, J. B. Jarnali, C. Krieger and F. A. Neugebauer, Magnetic-properties of 1,4-dihydro-1,2,4benzotriazin-4-yl radicals, Chem. Phys. Lett., 1994, 224, 569-575.

35 C. P. Constantinides, A. A. Berezin, G. A. Zissimou, M. Manoli, G. M. Leitus and P. A. Koutentis, The Suppression of Columnar $\pi$-Stacking in 3-Adamantyl-1-phenyl-1,4dihydrobenzo[e] [1,2,4]triazin-4-yl, Molecules, 2016, 21, 636.

36 C. P. Constantinides and P. A. Koutentis, Stable N- and N/S-Rich Heterocyclic Radicals: Synthesis and Applications, Adv. Heterocycl. Chem., 2016, 119, 173-207.

37 J. A. Grant, Z. Lu, D. E. Tucker, B. M. Hockin, D. S. Yufit, M. A. Fox, R. Kataky, V. Chechik and A. C. O'Donoghue, New Blatter-type radicals from a bench-stable carbene, Nat. Commun., 2017, 8, 15088.

38 G. A. Zissimou, A. A. Berezin, M. Manoli, C. Nicolaides, T. Trypiniotis and P. A. Koutentisa, 3,3', $3^{\prime \prime}$-(Benzene-1,3,5triyl)tris(1-phenyl-1H-benzo[e][1,2,4]triazin-4-yl): A C3 symmetrical Blatter-type triradical, Tetrahedron, 2020, 76, 131077.

39 C. P. Constantinides, E. Obijalska and P. Kaszyński, Access to 1,4-Dihydrobenzo[e][1,2,4]triazin-4-yl Derivatives, Org. Lett., 2016, 18, 916-919.

40 A. C. Savva, S. I. Mirallai, G. A. Zissimou, A. A. Berezin, M. Demetriades, A. Kourtellaris, C. P. Constantinides, C. Nicolaides, T. Trypiniotis and P. A. Koutentis, Preparation of Blatter Radicals via Aza-Wittig Chemistry: The Reaction of $\mathrm{N}$-Aryliminophosphoranes with 1-(Het)aroyl2-aryldiazenes, J. Org. Chem., 2017, 82, 7564-7575.

41 A. T. Gubaidullin, B. I. Buzykin, I. A. Litvinov and N. G. Gazetdinova, Molecular and Crystal Structure of a Superstable Free Radical, 1,3-Diphenyl-1,4-dihydro-1,2,4benzotriazin-4-yl, Russ. J. Gen. Chem., 2004, 74, 939-943.

42 A. A. Berezin, G. Zissimou, C. P. Constantinides, Y. Beldjoudi, J. M. Rawson and P. A. Koutentis, Correction to Route to Benzo- and Pyrido-Fused 1,2,4-Triazinyl Radicals via $N^{\prime}$-(Het)aryl- $N^{\prime}$-[2-nitro(het)aryl]hydrazides, J. Org. Chem., 2015, 80, 8943-8944.

43 G. Karecla, P. Papagiorgis, N. Panagi, G. A. Zissimou, C. P. Constantinides, P. A. Koutentis, G. Itskos and S. C. Hayes, Emission from the stable Blatter radical, New J. Chem., 2017, 41, 8604-8613.

44 T. Strassner, A. Weitz, J. Rose, F. Wudl and K. N. Houk, Toward ferromagnetic materials: prediction of a triplet ground state for heterocyclic polyacenes, Chem. Phys. Lett., 2000, 321, 459-462.

45 Y. Takahashi, Y. Miura and N. Yoshioka, Magnetic Interaction Observed in Hetero Biradical Derivatives Containing a 2,2,5,5-Tetramethylpyrrolin-1-yloxyl Unit as a Localized Spin Center, ChemPhysChem, 2018, 19, 175-179.

46 N. M. Gallagher, J. J. Bauer, M. Pink, S. Rajca and A. Rajca, High-Spin Organic Diradical with Robust Stability, J. Am. Chem. Soc., 2016, 138, 9377-9380.

47 N. Gallagher, H. Zhang, T. Junghoefer, E. Giangrisostomi, R. Ovsyannikov, M. Pink, S. Rajca, M. B. Casu and A. Rajca, Thermally and Magnetically Robust Triplet Ground State Diradical, J. Am. Chem. Soc., 2019, 141, 4764-4774.

$48 \mathrm{X} . \mathrm{Hu}, \mathrm{H}$. Chen, L. Zhao, M. Miao and Y. Zheng, Observation of a Solid-State-Induced Thermally Populated SpinTriplet State in Radical Regioisomers, Chem. Mater., 2019, 31, 10256-10262.

49 C. a. Di, F. Zhang and D. Zhu, Multi-functional integration of organic field-effect transistors (OFETs): advances and perspectives, Adv. Mater., 2013, 25, 313-330.

50 T. D. Nguyen, G. Hukic-Markosian, F. Wang, L. Wojcik, X.-G. Li, E. Ehrenfreund and Z. V. Vardeny, The hyperfine interaction role in the spin response of $\pi$-conjugated polymer films and spin valve devices, Synth. Met., 2011, 161, 598-603.

51 S. Majumdar, H. S. Majumdar, R. Laiho and R. Österbacka, Comparing small molecules and polymer for future organic spin-valves, J. Alloys Compd., 2006, 423, 169-171.

52 J. Z. Low, G. Kladnik, L. L. Patera, S. Sokolov, G. Lovat, E. Kumarasamy, J. Repp, L. M. Campos, D. Cvetko, 
A. Morgante and L. Venkataraman, The EnvironmentDependent Behavior of the Blatter Radical at the MetalMolecule Interface, Nano Lett., 2019, 19, 2543-2548.

53 L. L. Patera, S. Sokolov, J. Z. Low, L. M. Campos, L. Venkataraman and J. Repp, Resolving the UnpairedElectron Orbital Distribution in a Stable Organic Radical by Kondo Resonance Mapping, Angew. Chem., Int. Ed., 2019, 58, 11063-11067.

54 L. J. Keane, S. I. Mirallai, M. Sweeney, M. P. Carty, G. A. Zissimou, A. A. Berezin, P. A. Koutentis and F. Aldabbagh, Anti-Cancer Activity of Phenyl and Pyrid-2-yl 1,3Substituted Benzo[1,2,4]triazin-7-ones and Stable Free Radical Precursors, Molecules, 2018, 23, 574.

55 F. Ciccullo, N. M. Gallagher, O. Geladari, T. Chasse, A. Rajca and M. B. Casu, A Derivative of the Blatter Radical as a Potential Metal-Free Magnet for Stable Thin Films and Interfaces, ACS Appl. Mater. Interfaces, 2016, 8, 1805-1812.

56 I. S. Morgan, A. Peuronen, M. M. Hanninen, R. W. Reed, R. Clerac and H. M. Tuononen, 1-Phenyl-3-(pyrid-2-yl)benzo[e][1,2,4]triazinyl: the first "Blatter radical" for coordination chemistry, Inorg. Chem., 2014, 53, 33-35.

57 K. A. Hutchison, G. Srdanov, R. Menon, J. P. Gabriel, B. Knight and F. Wudl, A Pressure Sensitive Two-Dimensional Tetracyanoquinodimethane (TCNQ) Salt of a Stable Free Radical, J. Am. Chem. Soc., 1996, 118, 13081-13082.

58 A. S. Poryvaev, D. M. Polyukhov, E. Gjuzi, F. Hoffmann, M. Fröba and M. V. Fedin, Radical-Doped Metal-Organic Framework: Route to Nanoscale Defects and Magnetostructural Functionalities, Inorg. Chem., 2019, 58, 8471-8479.

59 X. Gong, M. H. Tong, S. H. Park, M. Liu, A. Jen and A. J. Heeger, Semiconducting polymer photodetectors with electron and hole blocking layers: high detectivity in the near-infrared, Sensors, 2010, 10, 6488-6496.

60 H. Lin, S. Ku, H. Su, C. Huang, Y. Lin, K. Wong and C. Wu, Highly Efficient Visible-Blind Organic Ultraviolet Photodetectors, Adv. Mater., 2005, 17, 2489-2493.

61 L. Salem and C. Rowland, The Electronic Properties of Diradicals, Angew. Chem., Int. Ed. Engl., 1972, 11, 92-111.

62 T. Kubo, A. Shimizu, M. Sakamoto, M. Uruichi, K. Yakushi, M. Nakano, D. Shiomi, K. Sato, T. Takui, Y. Morita and K. Nakasuji, Synthesis, Intermolecular Interaction, and Semiconductive Behavior of a Delocalized Singlet Biradical Hydrocarbon, Angew. Chem., 2005, 117, 6722-6726.

63 H. Koike, M. Chikamatsu and R. Azumi, J. y. Tsutsumi, K. Ogawa, W. Yamane, T. Nishiuchi, T. Kubo, T. Hasegawa and K. Kanai, Stable Delocalized Singlet Biradical Hydrocarbon for Organic Field-Effect Transistors, Adv. Funct. Mater., 2016, 26, 277-283.

64 F. Breher, Stretching bonds in main group element compounds-Borderlines between biradicals and closed-shell species, Coord. Chem. Rev., 2007, 251, 1007-1043.

65 Z. Sun, Q. Ye, C. Chi and J. Wu, Low band gap polycyclic hydrocarbons: from closed-shell near infrared dyes and semiconductors to open-shell radicals, Chem. Soc. Rev., 2012, 41, 7857-7889.
66 M. Abe, J. Ye and M. Mishima, The chemistry of localized singlet 1,3-diradicals (biradicals): from putative intermediates to persistent species and unusual molecules with a $\pi$-single bonded character, Chem. Soc. Rev., 2012, 41, 3808-3820.

67 C. Joachim, J. K. Gimzewski and A. Aviram, Electronics using hybrid-molecular and mono-molecular devices, Nature, 2000, 408, 541-548.

68 J. Bai, A. Daaoub, S. Sangtarash, X. Li, Y. Tang, Q. Zou, H. Sadeghi, S. Liu, X. Huang and Z. Tan, Anti-resonance features of destructive quantum interference in singlemolecule thiophene junctions achieved by electrochemical gating, Nat. Mater., 2019, 18, 364-369.

69 C. Huang, A. V. Rudnev, W. Hong and T. Wandlowski, Break junction under electrochemical gating: testbed for single-molecule electronics, Chem. Soc. Rev., 2015, 44, 889-901.

70 J. Liu, X. Huang, F. Wang and W. Hong, Quantum interference effects in charge transport through singlemolecule junctions: detection, manipulation, and application, Acc. Chem. Res., 2018, 52, 151-160.

71 J. Zheng, J. Liu, Y. Zhuo, R. Li, X. Jin, Y. Yang, Z.-B. Chen, J. Shi, Z. Xiao and W. Hong, Electrical and SERS detection of disulfide-mediated dimerization in single-molecule benzene-1, 4-dithiol junctions, Chem. Sci., 2018, 9, 5033-5038.

72 M. Baghernejad, X. Zhao, K. Baruël Ørnsø, M. Füeg, P. Moreno-García, A. V. Rudnev, V. Kaliginedi, S. Vesztergom, C. Huang and W. Hong, Electrochemical control of singlemolecule conductance by Fermi-level tuning and conjugation switching, J. Am. Chem. Soc., 2014, 136, 17922-17925.

73 I. Ratera and J. Veciana, Playing with organic radicals as building blocks for functional molecular materials, Chem. Soc. Rev., 2012, 41, 303-349.

74 S. Sanvito, Molecular spintronics, Chem. Soc. Rev., 2011, 40, 3336-3355.

75 J. McGuire, H. N. Miras, J. P. Donahue, E. Richards and S. Sproules, Ligand radicals as modular organic electron spin qubits, Chem. - Eur. J., 2018, 24, 17598-17605.

76 R. Frisenda, R. Gaudenzi, C. Franco, M. Mas-Torrent, C. Rovira, J. Veciana, I. Alcon, S. T. Bromley, E. Burzurí and H. S. Van der Zant, Kondo effect in a neutral and stable all organic radical single molecule break junction, Nano Lett., 2015, 15, 3109-3114.

77 M. Mannini, L. Sorace, L. Gorini, F. M. Piras, A. Caneschi, A. Magnani, S. Menichetti and D. Gatteschi, Selfassembled organic radicals on $\mathrm{Au}(111)$ surfaces: A Combined ToF-SIMS, STM, and ESR Study, Langmuir, 2007, 23, 2389-2397.

78 J. Liu, X. Zhao, Q. Al-Galiby, X. Huang, J. Zheng, R. Li, C. Huang, Y. Yang, J. Shi, D. Z. Manrique, C. J. Lambert, M. R. Bryce and W. Hong, Radical-Enhanced Charge Transport in Single-Molecule Phenothiazine Electrical Junctions, Angew. Chem., 2017, 56, 13061-13065.

79 L. Yuan, C. Franco, N. Crivillers, M. Mas-Torrent, L. Cao, C. S. Sangeeth, C. Rovira, J. Veciana and C. A. Nijhuis, 
Chemical control over the energy-level alignment in a twoterminal junction, Nat. Commun., 2016, 7, 1-10.

80 X. Hu, H. Chen, L. Zhao, M.-S. Miao, X. Zheng and Y. Zheng, Nitrogen-coupled blatter diradicals: the fused versus unfused bridges, J. Mater. Chem. C, 2019, 7, 10460-10464.

81 X. Hu, H. Chen, L. Zhao, M. Miao, J. Han, J. Wang, J. Guo, Y. Hu and Y. Zheng, Nitrogen analogues of Chichibabin's and Müller's hydrocarbons with small singlet-triplet energy gaps, Chem. Commun., 2019, 55, 7812-7815.

82 C. M. Rienstra, M. Hohwy, L. J. Mueller, C. P. Jaroniec, B. Reif and R. G. Griffin, Determination of Multiple Torsion-Angle Constraints in U-13C,15N-Labeled Peptides: 3D 1H-15N-13C-1H Dipolar Chemical Shift NMR Spectroscopy in Rotating Solids, J. Am. Chem. Soc., 2002, 124, 11908-11922.

83 S. D. Cady, K. Schmidt-Rohr, J. Wang, C. S. Soto, W. F. DeGrado and M. Hong, Structure of the amantadine binding site of influenza M2 proton channels in lipid bilayers, Nature, 2010, 463, 689-692.

84 F. Castellani, B. Van Rossum, A. Diehl, M. Schubert, K. Rehbein and H. Oschkinat, Structure of a protein determined by solid-state magic-angle-spinning NMR spectroscopy, Nature, 2002, 420, 99-102.

85 M. J. Bayro, T. Maly, N. R. Birkett, C. E. MacPhee, C. M. Dobson and R. G. Griffin, High-resolution MAS NMR analysis of PI3-SH3 amyloid fibrils: backbone conformation and implications for protofilament assembly and structure, Biochemistry, 2010, 49, 7474-7484.

86 V. S. Bajaj, M. L. Mak-Jurkauskas, M. Belenky, J. Herzfeld and R. G. Griffin, Functional and shunt states of bacteriorhodopsin resolved by $250 \mathrm{GHz}$ dynamic nuclear polarization-enhanced solid-state NMR, Proc. Natl. Acad. Sci. U. S. A., 2009, 106, 9244-9249.

87 G. T. Debelouchina, M. J. Bayro, P. C. van der Wel, M. A. Caporini, A. B. Barnes, M. Rosay, W. E. Maas and R. Griffin, Dynamic nuclear polarization-enhanced solidstate NMR spectroscopy of GNNQQNY nanocrystals and amyloid fibrils, Phys. Chem. Chem. Phys., 2010, 12, 5911-5919.

88 A. H. Linden, S. Lange, W. T. Franks, U. M. Akbey, E. Specker, B.-J. van Rossum and H. Oschkinat, Neurotoxin II bound to acetylcholine receptors in native membranes studied by dynamic nuclear polarization NMR, J. Am. Chem. Soc., 2011, 133, 19266-19269.

89 A. Lesage, M. Lelli, D. Gajan, M. A. Caporini, V. Vitzthum, P. Miéville, J. Alauzun, A. Roussey, C. Thieuleux and A. Mehdi, Surface enhanced NMR spectroscopy by dynamic nuclear polarization, J. Am. Chem. Soc., 2010, 132, 15459-15461.

90 O. Lafon, A. S. L. Thankamony, T. Kobayashi, D. Carnevale, V. Vitzthum, I. I. Slowing, K. Kandel, H. Vezin, J.-P. Amoureux and G. Bodenhausen, Mesoporous silica nanoparticles loaded with surfactant: low temperature magic angle spinning 13C and 29Si NMR enhanced by dynamic nuclear polarization, J. Phys. Chem. C, 2013, 117, 1375-1382.

91 T. Maly, G. T. Debelouchina, V. S. Bajaj, K.-N. Hu, C.-G. Joo, M. L. Mak-Jurkauskas, J. R. Sirigiri, P. C. van der Wel, J. Herzfeld and R. J. Temkin, Dynamic nuclear polarization at high magnetic fields, J. Chem. Phys., 2008, 128, 1-19.

92 Q. Z. Ni, E. Daviso, T. V. Can, E. Markhasin, S. K. Jawla, T. M. Swager, R. J. Temkin, J. Herzfeld and R. G. Griffin, High frequency dynamic nuclear polarization, Acc. Chem. Res., 2013, 46, 1933-1941.

93 A. J. Rossini, A. Zagdoun, M. Lelli, A. Lesage, C. Coperet and L. Emsley, Dynamic nuclear polarization surface enhanced NMR spectroscopy, Acc. Chem. Res., 2013, 46, 1942-1951.

94 J. Ardenkjaer-Larsen, I. Laursen, I. Leunbach, G. Ehnholm, L.-G. Wistrand, J. Petersson and K. Golman, EPR and DNP properties of certain novel single electron contrast agents intended for oximetric imaging, J. Magn. Reson., 1998, 133, 1-12.

95 A. Gandini and T. M. Lacerda, From monomers to polymers from renewable resources: Recent advances, Prog. Polym. Sci., 2015, 48, 1-39.

96 Y. Morita, S. Nishida, T. Murata, M. Moriguchi, A. Ueda, M. Satoh, K. Arifuku, K. Sato and T. Takui, Organic tailored batteries materials using stable open-shell molecules with degenerate frontier orbitals, Nat. Mater., 2011, 10, 947-951.

97 C. Friebe and U. S. Schubert, High-Power-Density Organic Radical Batteries, Top. Curr. Chem., 2017, 375, 19.

98 T. Suga, H. Ohshiro, S. Sugita, K. Oyaizu and H. Nishide, Emerging N-Type Redox-Active Radical Polymer for a Totally Organic Polymer-Based Rechargeable Battery, Adv. Mater., 2009, 21, 1627-1630.

99 T. Suga, S. Sugita, H. Ohshiro, K. Oyaizu and H. Nishide, p- and n-Type Bipolar Redox-Active Radical Polymer: Toward Totally Organic Polymer-Based Rechargeable Devices with Variable Configuration, Adv. Mater., 2011, 23, 751-754.

100 Y. Imada, H. Nakano, K. Furukawa, R. Kishi, M. Nakano, H. Maruyama, M. Nakamoto, A. Sekiguchi, M. Ogawa and T. Ohta, Isolation of hypervalent group-16 radicals and their application in organic-radical batteries, J. Am. Chem. Soc., 2016, 138, 479-482.

101 H. Maruyama, H. Nakano, M. Nakamoto and A. Sekiguchi, High-Power Electrochemical Energy Storage System Employing Stable Radical Pseudocapacitors, Angew. Chem., Int. Ed., 2014, 53, 1324-1328.

102 B. Häupler, U. S. Schubert, A. Wild, P. A. Koutentis and G. Zissimou, Verwendung benzotriazinyl-haltiger Polymere als Ladungsspeicher, DE102017005924, 2018-12-27. 